\title{
Highly Ordered Porous Silica Adsorbent with Dual Pore Size Regime for Bulky VOC Gas Sensing
}

\author{
Ji Sun Yun+, Young Hun Jeong, Joong-Hee Nam, Jeong-Ho Cho, and Jong-Hoo Paik
}

\begin{abstract}
Highly ordered porous materials having mesopores in the walls of macropores showed improved adsorption dynamics results for VOC molecules, especially bulky molecules. These meso/macroporous mataerials were synthesized by the dual templating method, and mesopore and macropore size were controlled by adjusting the templates for each pore size regime. In the case of adsorption and desorption of small VOC molecules (toluene), although meso/macroporous MCM-41 with smaller mesopore size showed improved results, meso/macroporous SBA-15 with larger mesopore size was not improved regardless of the existence of macropores, since there was no limitation of movement through the larger mesopore. However, the adsorption dynamics of bulky VOC molecules (p-xylene) over meso/macroporous SBA-15 were drastically improved by increasing the macropore size.
\end{abstract}

Keywords : Highly ordered porous materials, Biporous materials, Dual pore size regime, MCM-41, SBA-15, Adsorption of VOCs

\section{INTRODUCTION}

Well ordered porous materials have been becoming increasingly important in various fields, particularly as catalysts, for adsorption, separation and as electrodes for battery or supercapacitor, due to their large surface area and ability to interact with atoms, ions, and molecules. MCM-41 and SBA-15 have generally been used as typical well ordered mesoporous materials, since they were reported by the Beck group [1, 2] and Stucky group [3]. These materials have very narrow pore size distributions and high surface areas, and can be synthesized using the self-assembly properties of surfactants or supramolecules.

Well ordered meso/macroporous materials have been studied by various researchers [4-7], because the biporous materials have the multiple benefits of high surface area, as a consequence of their mesopore size regime, and easy access to active sites, derived from their macropore size regime.

Herein, meso/macroporous materials having mesopores

Electronic Materials Convergence Division, Korea Institute of Ceramic Engineering and Technology, Seoul 153-023, Korea

${ }^{+}$Corresponding author: susubin@kicet.re.kr

(Received: Apr. 25, 2013, Accepted : May. 20, 2013)

This is an Open Access article distributed under the terms of the Creative Commons Attribution Non-Commercial License(http://creativecommons.org/licenses/bync/3.0)which permits unrestricted non-commercial use, distribution, and reproduction in any medium, provided the original work is properly cited. in the walls of macropores were synthesized by a dual templating method, as shown in Fig. 1. Two types of mesoporous materials, MCM-41 and SBA-15, were studied, and macropore size was controlled by adjusting the polystyrene (PS) bead size. The effect of the existing macropore was researched by analyzing the adsorption and desorption properties of volatile organic compounds (VOCs) such as toluene and p-xylene.
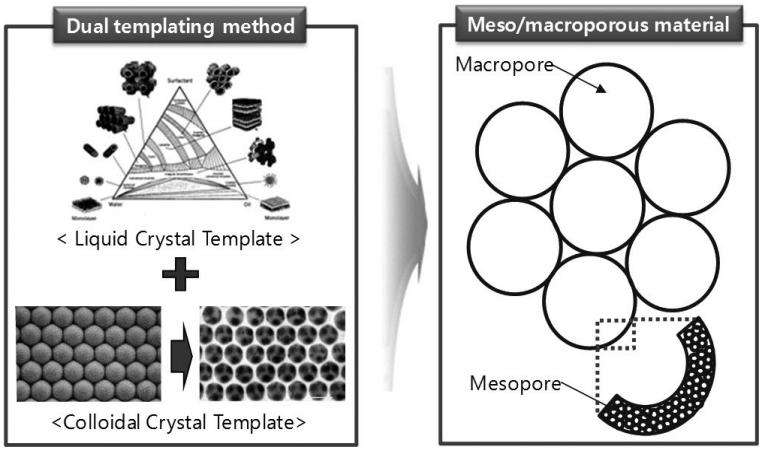

Fig. 1. Schematic diagram of dual templating method and structure of meso/macroporous materials.

\section{EXPERIMENTAL}

PS beads for macropore template were prepared by emulsifier-free emulsion polymerization [8]. Styrene 
monomer in a solution of initiator $\left(\mathrm{K}_{2} \mathrm{~S}_{2} \mathrm{O}_{8}\right)$ and deionized water was polymerized under a nitrogen atmosphere for 24 hours at $70^{\circ} \mathrm{C}$. PS beads were assembled by icecrystallization. The beads were recovered by filtration, and dried under vacuum at $60^{\circ} \mathrm{C}$ for 24 hours.

Biporous silicates with mesopores and macropores were synthesized by a dual-templating method [7]. Mesophase for meso/macroporous MCM-41 was prepared according to the process described by Ryoo et al. [9]. PS beads $\left(\mathrm{SiO}_{2}\right.$ : PS bead $=1: 2$, weight ratio) were added into the surfactant (cetyltrimethylammoniumchloride) solution at $60^{\circ} \mathrm{C}$, and then $9 \mathrm{wt} \%$ sodium silicate solution (silica source) was added dropwise into the mixture. After vigorous stirring for $1 \mathrm{hr}$, the mixture was aged at $100^{\circ} \mathrm{C}$ for 2 days and adjusted to $\mathrm{pH} 10$ at room temperature. This process of $\mathrm{pH}$ adjustment was repeated twice. The precipitate was filtered, dried at $100^{\circ} \mathrm{C}$, and calcined at $550{ }^{\circ} \mathrm{C}$ for $5 \mathrm{hr}$.

For the synthesis of meso/macroporous SBA-15, the mother liquor for SBA-15 mesophase was prepared based on the procedures reported by the Stucky group [10]. Pluronic $123\left(\mathrm{EO}_{20} \mathrm{PO}_{70} \mathrm{EO}_{20}\right)$, amphiphilic block copolymer, was dissolved in $1.6 \mathrm{M} \mathrm{HCl}$ solution with vigorous stirring, and then PS beads $\left(\mathrm{SiO}_{2}\right.$ : PS bead $=1$ : 2 , weight ratio) were added into the mixture with vigorous stirring at room temperature. Tetraethylorthosilicate (silica source) was added to the tri-block copolymer solution and stirred for $1 \mathrm{hr}$ at $35^{\circ} \mathrm{C}$. Sol-gel reaction was carried out at $35^{\circ} \mathrm{C}$ for $24 \mathrm{hr}$ and sequentially at $100^{\circ} \mathrm{C}$ for $12 \mathrm{hr}$. The precipitate was filtered, dried at $80^{\circ} \mathrm{C}$, and calcined at $550{ }^{\circ} \mathrm{C}$ for $5 \mathrm{hr}$.

$0.2 \mathrm{~g}$ of an adsorbent (meso/macroporous MCM-41 and SBA-15) was applied for the adsorption of 1000 ppm VOC molecules such as toluene and p-xylene with $50 \mathrm{~cm} 3 / \mathrm{min}$ of feed flow rate at $35^{\circ} \mathrm{C}$, and then temperature programmed desorption (TPD) of the adsorbate (VOC molecules) was run from $35^{\circ} \mathrm{C}$ to $300^{\circ} \mathrm{C}$ at a heating rate of $10{ }^{\circ} \mathrm{C} / \mathrm{min}$.

\section{RESULTS AND DISCUSSIONS}

Two kinds of monodispersed PS beads as a macropore template, PS1 $(250 \mathrm{~nm})$ and PS2 (500 nm), were prepared by ice-crystallization as shown in Fig. 2 (a)-(d). The PS bead size generally depends on the ratio of water/styrene monomer and the amount of initiator $\left(\mathrm{K}_{2} \mathrm{~S}_{2} \mathrm{O}_{8}\right)$. The bigger size of PS beads was normally observed by decreasing the initiator concentration and by increasing the amount of styrene monomer. Silica sol solution with surfactant as a mesopore template passed through the PS beads array as a macropore template by capillary force, and the sol-gel reaction was completed by heat treatment. After calcination, the dual pore size structure consisting of mesopores in the walls of macropores was obtained, as shown in Fig. 3. The size of mesopore of MCM41(1:2)PS1 and MCM-41(1:2)PS2 was about $3 \mathrm{~nm}$, and the macropore size of these matarials was about $250 \mathrm{~nm}$ and $500 \mathrm{~nm}$, respectively. SBA-15(1:2)PS1 and SBA15(1:2)PS2 had a bigger mesopore size (about $5 \mathrm{~nm}$ ) than MCM-41, and the macropore size of these matarials was about $250 \mathrm{~nm}$ and $500 \mathrm{~nm}$, respectively. The BET surface area of MCM-41(1:2)PS1 and MCM-41(1:2)PS2 was $1398 \mathrm{~m}^{2} / \mathrm{g}$ and $1349 \mathrm{~m}^{2} / \mathrm{g}$, respectively, similar to the 1358 $\mathrm{m}^{2} / \mathrm{g}$ for MCM-41. The BET surface area of SBA15(1:2)PS1 and SBA-15(1:2)PS2 was $793 \mathrm{~m}^{2} / \mathrm{g}$ and 828 $\mathrm{m}^{2} / \mathrm{g}$, respectively, similar to the $861 \mathrm{~m}^{2} / \mathrm{g}$ for SBA- 15 . These results seem to support the maintenance of the mesopore structure regardless of the existence of macropores.

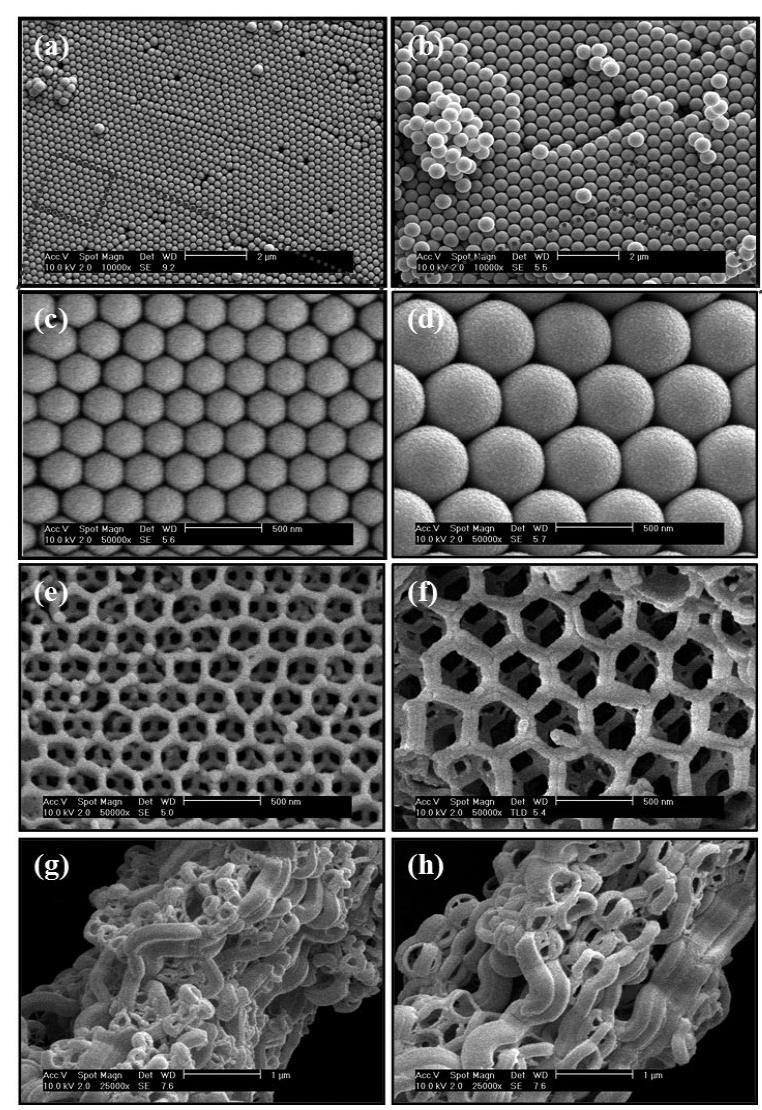

Fig. 2. SEM images of (a) and (c) PS1 (250 nm), (b) and (d) PS2 (500 nm), (e) MCM-41(1:2)PS1, (f) MCM-41(1:2)PS2, (g) SBA-15(1:2)PS1, and (h) SBA-15(1:2)PS2. 

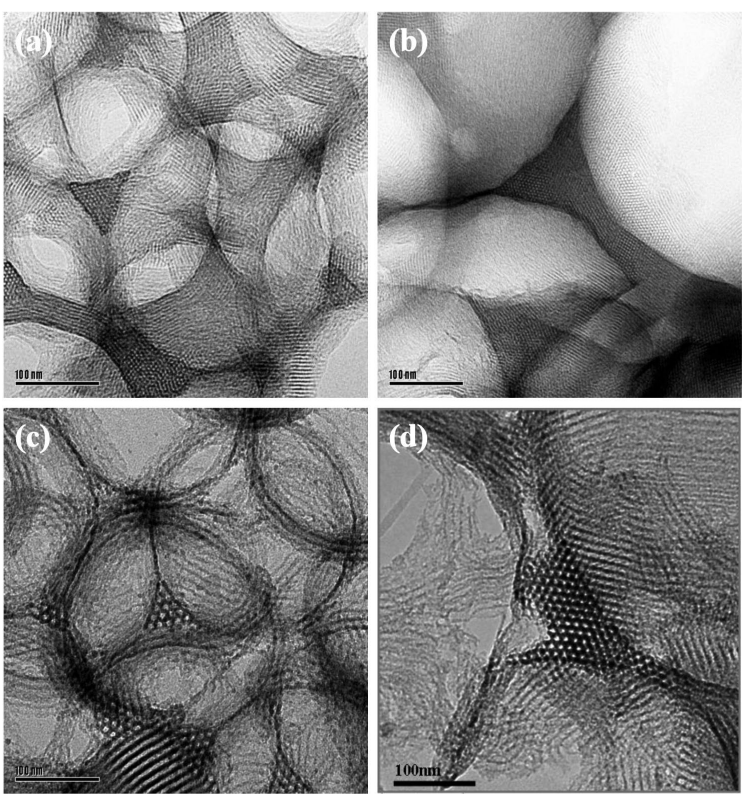

Fig. 3. TEM images of mesopores in the macropore wall of (a) MCM-41(1:2)PS1, (b) MCM-41(1:2)PS2, (c) SBA15(1:2)PS1, and (d) SBA-15(1:2)PS2.
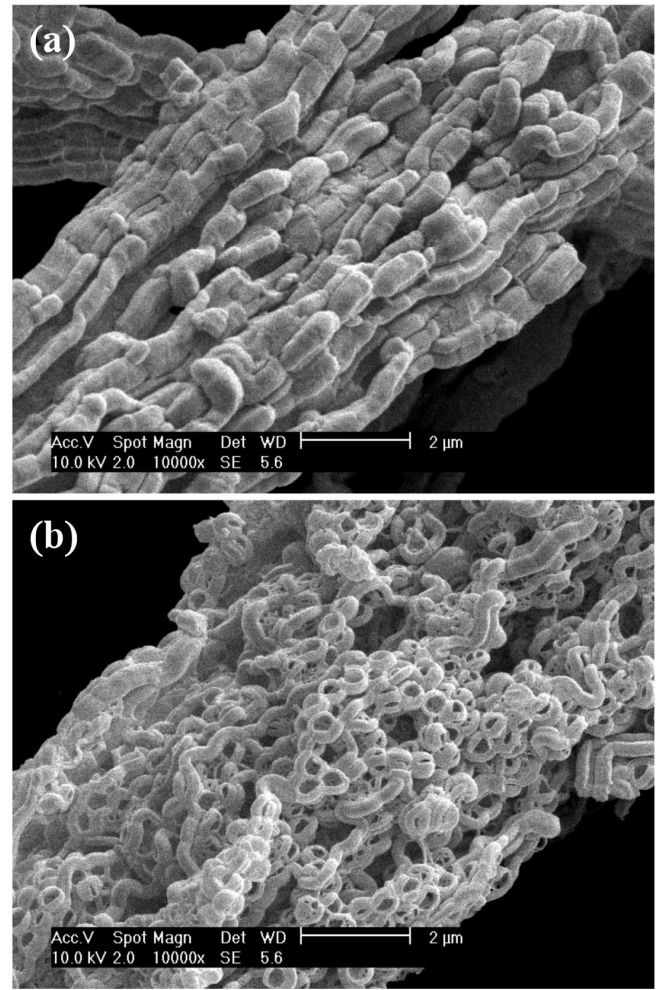

Fig. 4. SEM images of (a) SBA-15 and (b) SBA-15 with $500 \mathrm{~nm}$ macropores.

The macropore structure reversely replicated the structure of the highly ordered PS beads, as shown in Fig. 2 (e)-(h). The bigger the PS bead that was used as a macropore template, the largger the pore size that was observed. Although MCM-41(1:2)PS1 and MCM41(1:2)PS2 showed extact imprints of the PS beads array, the morphology of SBA-15(1:2)PS1 and SBA-15(1:2)PS2 was slightly different. That is because an inherent unique structure of SBA-15 still remained regardless of presence of macropores, as shown in Fig. 4. The crystallinity of the PS beads array had to undergo the influences of combined forces such as electrostatic and hydrogen-bonding interaction, to form the unique morphology of SBA-15, and then the macropore structures of biporous SBA-15 were not well ordered and had a different morphology compared with biporous MCM-41.

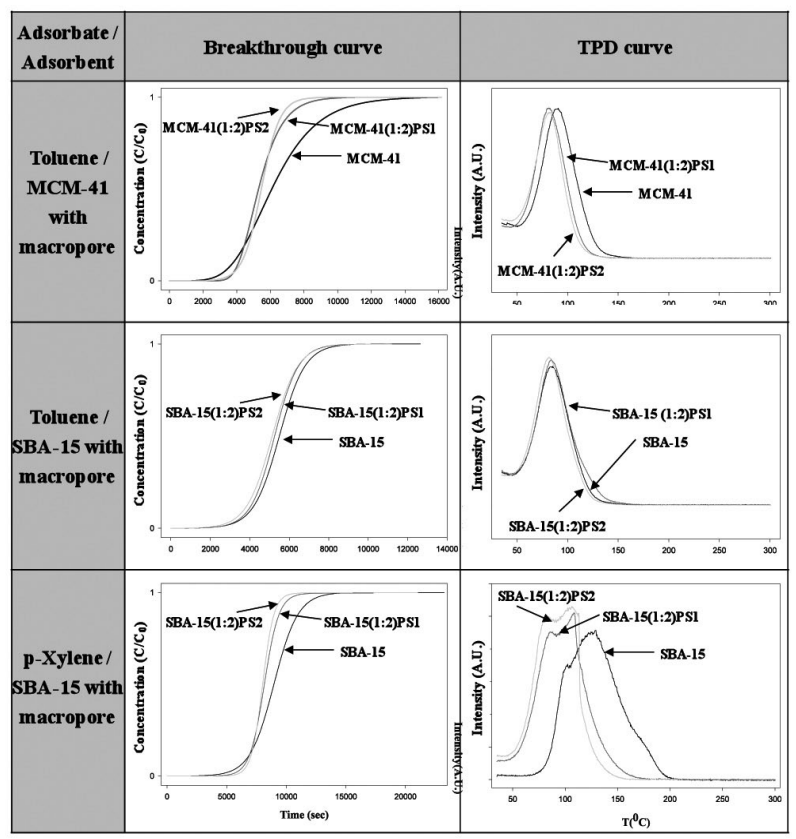

Fig. 5. Breakthrough curve of toluene and p-xylene at 50 $\mathrm{STPcm} / \mathrm{min}$ at $35^{\circ} \mathrm{C}$ and TPD curve of toluene and $\mathrm{p}$ xylene for meso/macroporous MCM-41 and SBA-15.

The breakthrough curves for the adsorption and TPD (Temperature Programmed Desorption) curves of toluene and p-xylene over biporous MCM-41 and SBA-15 with different macropore size were observed, as shown in Fig. 5. In the case of the adsorption and desorption of small VOC molecules (toluene) over meso/macroporous MCM-41, although the total amount of adsorption was similar to pure MCM-41, a steeper slope of the breakthrough curve and a desorption peak at a lower temperature were observed with increasing macropore size. These results seem to demonstrate that the adsorption capacity was provided mainly by the mesopores, and the macropores provided easy accessibility for the adsorbate. The adsorption 
dynamics of small VOC molecules (toluene) over meso/macroporous SBA-15 was similar to those over pure SBA-15. This is because the mesopore size of SBA-15 (about $5 \mathrm{~nm}$ ) was bigger than that of MCM-41 (about 3 $\mathrm{nm}$ ), and small VOC molecules (toluene) seem to move easily through the mesopore of SBA-15. However, when bulky VOC molecules ( $\mathrm{p}$-xylene) were adsorbed over meso/macroporous SBA-15, with increasing macropore size, the slope of the breakthrough curve was slightly steeper, and the TPD curve was also shifted to a lower temperature region. These results seem to suggest that the mass transter of an adsorbate, especially a bulky adsorbate, was improved by the existence of the macropore structure.

\section{CONCLUSIONS}

Highly ordered porous materials having mesopores in the walls of macropores were synthesized by the dual templating method. Meso/macroporous materials with different mesopore size (about $3 \mathrm{~nm}$ (MCM-41) and $5 \mathrm{~nm}$ (SBA-15)) were prepared, and macropore size (about 250 $\mathrm{nm}$ (PS1) and $500 \mathrm{~nm}$ (PS2)) was controlled by adjusting PS beads size. In the case of the adsorption and desorption of small VOC molecules (toluene), although the meso/macroporous MCM-41 with smaller mesopore size showed improved results, the adsorption dynamics over meso/macroporous SBA-15 with larger mesopore size were not improved, since there were no problems of movement through the larger mesopore. However, the adsorption dynamics of bulky VOC molecules ( $p$-xylene) over meso/macroporous SBA-15 were drastically improved by increasing the macropore size; it exhibited a steeper slope of the breakthrough curve and a shift of the peak of the TPD curve to a lower temperature region. These results seem to support the conclusion that the adsorption capacity was mainly influenced by the mesopores, and the macropores provided easy accessibility for the adsorbate.

\section{ACKNOWLEDGMENT}

This work was supported by KICET R\&D Project funded by Korea Institute of Ceramic Engineering and Technology.

\section{REFERENCES}

[1] C. T. Kresge, M. E. Leonowicz, W. J. Roth, J. C. Vartulli, and J. S. Beck, "Ordered mesoporous molecular sieves synthesized by a liquid crystal template mechanism”, Nature, Vol. 359, pp. 710-712, 1992.

[2] J. S. Beck, J. C. Vartulli, W. J. Roth, M. E. Leonowicz, C. T. Kresge, K. D. Schmitt, C. T. W. Chu, D. H. Olson, and E. W. Sheppard, "A new family of mesoporous molecular sieves prepared with liquid crystal templates", J. Am. Chem. Soc., Vol. 114, pp. 10834-10843, 1992.

[3] A. Firouzi, D. Kumar. L. M. Bull, T. Beiser, P. Sieger, Q. Huo, S. A. Walker, J. A. Zasadxinsky, C. Glinka, J. Nicol, K. Margolese, G. D. Stucky, and B. F. Chmelka, "Cooperative organization of inorganic-surfactant and biomimetic assemblies”, Science, Vol. 267, pp. 1138$1143,1995$.

[4] M. Antonietti, B. Berton, C. Goltner, and H. Hentze, "Synthesis of mesoporous silica with large pores and bimodal pore size distribution by templating of polymer latices", Adv. Mater. , Vol. 10, pp. 154-159, 1998.

[5] B. Lebeau, C. E. Fowler, S. Mann, C. Farcet, B. Charleux, and C. Sanchez, "Synthesis of hierarchically ordered dye-functionalised mesoporous silica with macroporous architecture by dual templating", $J$. Mater. Chem. , Vol. 10, pp. 2105-2108, 2000.

[6] Ch. Danumah, S. Vaudreuil, L. Bonneviot, M. Bousmina, S. Giasson, and S. Kaliaguine, "Synthesis of macrostructured MCM-48 molecular sieves", Micropor. Mesopor. Mat., Vol. 44, pp. 241-247, 2001.

[7] C. G. Oh, Y. K. Baek, and S. K. Ihm, "Synthesis of skeletal-structured biporous silicate powders through microcolloidal crystal templating", Adv. Mater., Vol. 17, pp. 270-273, 2005.

[8] J. H. Kim, M. Chainet, M. S. El-asser, and J. W. Vanderhoff, "Preparation of highly sulfonated polystyrene model colloids", J. Polym. Sci. Pol. Chem., Vol. 27, pp. 3187-3199, 1989.

[9] R. Ryoo, and S. Jun, "Improvement of hydrothermal stability of MCM-41 using salt effect during the crystallization process", J. Phys. Chem. B, Vol. 101, pp. 317-320, 1997.

[10] Y. J. Han, J. M. Kim, and G. D. Stucky, "Preparation of noble metal nanowires using hexagonal mesoporous silica SBA-15", Chem. Mater. Vol. 12, pp, 2068-2069, 2000. 